\title{
The Mycobacterium avium ssp. paratuberculosis specific mptD gene is required for maintenance of the metabolic homeostasis necessary for full virulence in mouse infections
}

\author{
Thorsten Meißner ${ }^{1}$, Elke Eckelt ${ }^{1}$, Tina Basler ${ }^{1}$, Jochen Meens ${ }^{1}$, Julia Heinzmann ${ }^{1 \dagger}$, \\ Abdulhadi Suwandi ${ }^{2}$, Walter M. R. Oelemann ${ }^{3,4}$, Sandra Trenkamp ${ }^{5}$, Otto Holst ${ }^{4}$, Siegfried Weiss $^{2}$, \\ Boyke Bunk $^{6,7}$, Cathrin Spröer ${ }^{6,7}$, Gerald-F. Gerlach ${ }^{1+}$ and Ralph Goethe ${ }^{1 *}$
}

\footnotetext{
${ }^{1}$ Department of Infectious Diseases, Institute for Microbiology, University of Veterinary Medicine Hannover, Hannover, Germany

${ }^{2}$ Helmholtz Centre for Infection Research, Molecular Immunology, Braunschweig, Germany

${ }^{3}$ Departamento de Imunologia, Instituto de Microbiologia Paulo Góes, Universidade Federal do Rio de Janeiro (UFRJ), Rio de Janeiro, Brazil

${ }^{4}$ Division of Structural Biochemistry, Research Center Borstel, Leibniz-Center for Medicine and Biosciences, Borstel, Germany

${ }^{5}$ Metabolomic Discoveries GmbH, Potsdam-Golm, Germany

${ }^{6}$ Bioinformatics, Leibniz Institute DSMZ-German Collection of Microorganisms and Cell Cultures, Braunschweig, Germany

7 German Centre of Infection Research, Partner Site Hannover-Braunschweig, Braunschweig, Germany
}

Edited by:

Wolfgang Eisenreich, Technische Universität München, Germany

\section{Reviewed by:}

Maria Júlia Manso Alves, University of São Paulo, Brazil

Adel M. Talaat, University of

Wisconsin Madison, USA

\section{${ }^{*}$ Correspondence:}

Ralph Goethe, Zentrum für

Infektionsmedizin, Institut für

Mikrobiologie, Stiftung Tierärztliche

Hochschule Hannover, Bischofsholer

Damm 15, 30173 Hannover,

Germany

e-mail: ralph.goethe@

tiho-hannover.de

${ }^{t}$ Present address:

Julia Heinzmann, Institute of Farm Animal Genetics, Federal Research Institute of Animal Health,

Friedrich-Loeffler-Institut, Neustadt, Germany;

Gerald-F. Gerlach, Innovative

Veterinary Diagnostics Laboratory

$\mathrm{GmbH}$, Hannover, Germany
Mycobacterium avium subspecies paratuberculosis (MAP) causes Johne's disease, a chronic granulomatous enteritis in ruminants. Furthermore, infections of humans with MAP have been reported and a possible association with Crohn's disease and diabetes type I is currently discussed. MAP owns large sequence polymorphisms (LSPs) that were exclusively found in this mycobacteria species. The relevance of these LSPs in the pathobiology of MAP is still unclear. The mptD gene (MAP3733c) of MAP belongs to a small group of functionally uncharacterized genes, which are not present in any other sequenced mycobacteria species. mptD is part of a predicted operon (mptABCDEF), encoding a putative ATP binding cassette-transporter, located on the MAP-specific LSP14. In the present study, we generated an mptD knockout strain (MAP $\Delta m p t D$ ) by specialized transduction. In order to investigate the potential role of $m p t D$ in the host, we performed infection experiments with macrophages. By this, we observed a significantly reduced cell number of MAP $\Delta m p t D$ early after infection, indicating that the mutant was hampered with respect to adaptation to the early macrophage environment. This important role of $m p t D$ was supported in mouse infection experiments where MAP $\Delta m p t D$ was significantly attenuated after peritoneal challenge. Metabolic profiling was performed to determine the cause for the reduced virulence and identified profound metabolic disorders especially in the lipid metabolism of MAP $\Delta m p t D$. Overall our data revealed the mptD gene to be an important factor for the metabolic adaptation of MAP required for persistence in the host.

Keywords: Mycobacterium infections, metabolism, lipids, macrophages, survival

\section{INTRODUCTION}

Mycobacterium avium subspecies paratuberculosis (MAP) belongs to the M. avium complex (MAC), which comprises subspecies of $M$. avium with different extents of host adaptation and virulence. For instance M. avium subsp. hominissuis is found ubiquitously in the environment and causes opportunistic infections in humans, pigs and ruminants, whereas $M$. avium subsp. avium is the causative agent of tuberculosis in birds (Thorel et al., 1990; Mijs et al., 2002; Dvorska et al., 2003; Dhama et al., 2011; Ignatov et al., 2012). In contrast, MAP is an obligate pathogen for ruminants causing Johne's disease (JD, paratuberculosis) - a chronic granulomatous enteritis (Kreeger, 1991; Harris and Barletta, 2001). Moreover, infections of humans with MAP have been reported and a possible association with Crohn's disease and more recently with diabetes type I has been discussed (Greenstein, 2003; Feller et al., 2007; Mendoza et al., 2009; Rani et al., 2010; Rosenfeld and Bressler, 2010; Cossu et al., 2011; Chiodini et al., 2012; Naser et al., 2014).

JD is characterized by an extending transmural inflammation of the intestine without caesification of the granulomas. Noteworthy, lesions in other areas are less common, indicating a specific tropism of MAP for the intestine which is not seen in other mycobacteria (Buergelt et al., 1978; Clarke, 1997; Burrells et al., 1998). The intestinal tropism of MAP is particularly evident in ruminants, but it has become apparent that the organism has a much broader host range including monogastric species such 
as carnivore (fox, stoats), aves (crow and jackdaw), lagomorpha (rabbits) and recently miniature donkeys (Greig et al., 1999; Beard et al., 2001; Glanemann et al., 2008; Stief et al., 2012; Carta et al., 2013).

The pathobiology of MAP infection including its tropism to the gut is still unresolved. After crossing the intestinal barrier, MAP is taken up by intestinal macrophages and there is common consensus that the persistence in these macrophages is the key step in MAP infection (Ryan et al., 2014). Nevertheless, the persistence in macrophages, characterized by inhibition of the phagosomal maturation process, altered antigen processing and presentation is a common feature of any pathogenic mycobacterial species and might not explain the characteristics of intestinal MAP infection (Kuehnel et al., 2001; Hostetter et al., 2002; Vergne et al., 2004). However, MAP additionally inhibits T cell and Dendritic cell (DC) activation and restricts the macrophage inflammatory cytokine response in cell culture systems (zur Lage et al., 2003; Basler et al., 2010, 2013). Thus, it seems that MAP persists and survives in its intestinal niche by subverting the immune defense mechanisms of the host and therefore might remain locally restricted to the intestine for long time (Atreya et al., 2014). In addition, on the bacterial side consequences of infection are characterized by a strong metabolic adaptation to the intestinal environment of the host (Weigoldt et al., 2011, 2013), which suggest that this capacity considerably adds to MAP pathobiology.

Within the MAC, MAP exhibits particular phenotypic features in culture. Thus, MAP growth in culture is dependent on mycobactin supplementation, extremely slow with the average doubling time of 22-26h (other MAC ssp. 10-12 h), and shows a strong tendency to clump formation (Merkal and Curran, 1974). Differences in the phenotype and virulence of MAP might be linked to MAP specific genes ( $\mathrm{Li}$ et al., 2005) and/or the acquisition, loss and rearrangement of specific genetic elements (Alexander et al., 2009). Sixteen large sequence polymorphisms (LSPs) were exclusively found in MAP. Six out of these 16 LSPs are common in all MAP strains and considered to be genomic insertions. These insertions comprise $\sim 125 \mathrm{~kb}$ of DNA with 82 open reading frames (ORFs), with most of them being not of mycobacterial origin but exhibiting similarities to genes from environmental actinomycetes (Marri et al., 2006). Yet it is not clear whether the genes encoded on MAP-specific LSPs contribute to the phenotype and pathogenicity of MAP.

Previously, we had identified a MAP-specific putative $38 \mathrm{~kb}$ pathogenicity island which is located on LSP14, the largest LSP found in MAP. LSP14 harbors mostly genes which encode for proteins with predicted functions in metal metabolism (Stratmann et al., 2004). Within the $38 \mathrm{~kb}$ DNA region, a predicted operon $m p t$ ABCDEF encodes for two putative ATP binding cassette transporters. The mptABCDEF operon (MAP3736c-31c) exhibits the highest similarity to other genera of the order Actinomycetales such as Salinispora or Bifidobacter and to a lesser extent to other mycobacteria. In addition, these genes have no other orthologs in MAP (data not shown). Among the operon genes, $m p t \mathrm{D}$ is unique in MAP within the genus of Mycobacterium since it is present in all sequenced cattle- and sheep-type MAP strains, but it is not found in any other so far sequenced mycobacterial species, even not in other subspecies of the MAC. Interestingly, mptD was found to be surface-exposed and expressed during infection (Stratmann et al., 2004; Shin et al., 2006). In addition, Cossu and colleagues found antibodies against $m p t \mathrm{D}$ in sera of type I diabetes mellitus patients (Cossu et al., 2011), suggesting a possible role of $m p t \mathrm{D}$ in MAP pathogenicity in humans.

In the present study, we used specialized transduction to generate a $m p t \mathrm{D}$ knockout strain. By different comparative analyses we found that the gene is important for the metabolic homeostasis of MAP, which appears to be necessary for adaptation to the macrophage environment and survival in a mouse infection model.

\section{MATERIALS AND METHODS}

\section{BACTERIAL STRAINS, CHEMICALS, AND GROWTH CONDITIONS}

All chemicals were purchased from Sigma-Aldrich (Munich, Germany) if not stated otherwise. All bacterial strains, phages, and plasmids are listed in Table S1. The Escherichia coli strains DH5 $\alpha$ and HB101 and the M. smegmatis mc $^{2} 155$ strain were cultured in Luria-Bertani (LB) broth or on LB agar plates (Roth, Karlsruhe, Germany) containing appropriate antibiotics with a concentration of $100 \mu \mathrm{g} / \mathrm{ml}$. The E. coli strains DH5 $\alpha$ and HB101 were used for cloning of homologous regions and for construction of the allelic exchange substrate (AES) in pYUB854. Additionally, E. coli $\mathrm{HB} 101$ was used for the in vitro $\lambda$-packaging reaction (GIGApack ${ }^{\circledR}$ II plus kit, Stratagene, La Jolla, CA, USA). For transformation experiments, competent E. coli HB101 were prepared following standard procedures (Sambrook and Russell, 2001). Liquid cultures of E. coli and M. smegmatis were grown at $37^{\circ} \mathrm{C}$ in a shaking incubator. M. smegmatis $\mathrm{mc}^{2} 155$ was used for the generation of high titer phage lysates and phage construction as described (Carriere et al., 1997). M. avium subsp. paratuberculosis strain DSM 44135 (MAPwt) (Stratmann et al., 2004) was grown in Middlebrook 7H9 broth (MB7H9) or on Middlebrook 7H10 agar supplemented with 10\% OADC and mycobactin J ( $2 \mathrm{mg} / \mathrm{l}$; Allied Monitor, Fayette, USA). MB7H9 medium was further supplemented with Tween ${ }^{\circledR} 80(0.05 \%$ final concentration) unless stated otherwise. For growth experiments, MAPwt and the mutant strain MAP $\Delta m p t \mathrm{D}$ were cultured in supplemented MB7H9 medium until an $\mathrm{OD}_{600}$ of 3.0 was reached. The bacteria were then harvested, washed two times with phosphatebuffered saline (PBS) and diluted in supplemented MB7H9 without Tween ${ }^{\circledR} 80$ to an $\mathrm{OD}_{600}$ of 0.2. Bacteria were cultivated with stirring at $120 \mathrm{rpm}$ at $37^{\circ} \mathrm{C}$ and $\mathrm{OD}_{600}$ was measured every 2-3 days until entry of stationary phase.

\section{DNA TECHNIQUES}

Chromosomal mycobacterial DNA was prepared according to standard procedures (Belisle and Sonnenberg, 1998). Plasmids of E. coli were isolated using the NucleoSpin Plasmid kit (MachereyNagel, Düren, Germany) according to the manufacture's protocol. Southern blot analyses were performed with EcoRV-restricted chromosomal DNA according to standard protocols (Sambrook and Russell, 2001), using a $\alpha^{32}$-P-dCTP labeled PCR fragment obtained with primers omptD3a and omptD4a as a DNA probe. After hybridization, membranes were exposed to X-ray film (Kodak X-OMAT ${ }^{\circledR}$ Biomax, Sigma Aldrich GmbH, Deisenhofen, 
Germany). Polymerase-chain-reactions (PCR) were run on a Mastercycler system (Eppendorf, Hamburg, Germany), using HotStart HiFidelity Polymerase (Qiagen, Hilden, Germany) and the following conditions: $95^{\circ} \mathrm{C}$ for $10 \mathrm{~min}, 95^{\circ} \mathrm{C}$ for $45 \mathrm{~s}, 58^{\circ} \mathrm{C}$ for $60 \mathrm{~s}$, and $72^{\circ} \mathrm{C}$ for $60 \mathrm{~s}$. The oligonucleotides are listed in Table S1.

\section{CONSTRUCTION OF MAP $\Delta$ mptD}

The construction of the specialized transducing mycobacteriophage containing the AES was performed according to Park and colleagues (Park et al., 2008) with slight modifications. A detailed protocol is given in the supplementary methods file. Briefly, in order to generate an mptD (MAP3733c) deletion in MAP, two oligonucleotide primer pairs (Table S1) were generated to amplify the up- and downstream flanking regions of the $m p t \mathrm{D}$ gene resulting in an deletion of 518 bps of the $m p t \mathrm{D}$ ORF upon restriction digest and ligation of the amplified products into the cosmid vector pYUB854 (Bardarov et al., 2002). The resulting construct pMP1310 was introduced into the mycobacterial phage vector phAE87 (Bardarov et al., 1997), resulting in phage phAE111. To construct a MAP $\Delta m p t \mathrm{D}$ mutant, MAP was cultured in MB7H9 medium to $\mathrm{OD}_{600}$ of 1.0. Bacterial suspensions of MAP, free of clumps, were transduced and plated on MB7H10 agar plates containing $50 \mu \mathrm{g} / \mathrm{ml}$ hygromycin $\mathrm{B}$ and incubated at $37^{\circ} \mathrm{C}$ for up to 12 weeks. Successful recombination was confirmed by
PCR, Southern blot and quantitative real-time PCR (qRT-PCR) analyses (Figures 1A-C).

\section{PacBio RSII RESEQUENCING STUDY}

SMRTbell ${ }^{\mathrm{TM}}$ template library was prepared according to the instructions from PacificBiosciences, Menlo Park, CA, USA, following the Procedure and Checklist Greater than $10 \mathrm{~kb}$ Template Preparation and Sequencing. Briefly, for preparation of $10 \mathrm{~kb}$ libraries, $\sim 10 \mu \mathrm{g}$ genomic DNA were end-repaired and ligated overnight to hairpin adapters applying components from the DNA/Polymerase Binding Kit P4 from Pacific Biosciences, Menlo Park, CA, USA. Reactions were carried out according to the manufacturer's instructions. SMRTbell ${ }^{\mathrm{TM}}$ template was Exonuclease treated for removal of incompletely formed reaction products. Conditions for annealing of sequencing primers and binding of polymerase to purified SMRTbell ${ }^{\mathrm{TM}}$ template were assessed with the Calculator in RS Remote, PacificBiosciences, Menlo Park, CA, USA. SMRT sequencing was carried out on the PacBio RSII (PacificBiosciences, Menlo Park, CA, USA) taking one 180-min movie for each SMRT cell. In total 1 SMRT cell was run.

\section{RNA EXTRACTION AND QUANTITATIVE REAL-TIME PCR}

Total RNA was extracted from MAPwt and MAP $\Delta m p t \mathrm{D}$ grown to mid log phase $\left(\mathrm{OD}_{600}\right.$ of 1.0$)$ using a TRIzol ${ }^{\circledR}$ protocol according to Rustad et al. (2009). RNA was additionally purified using
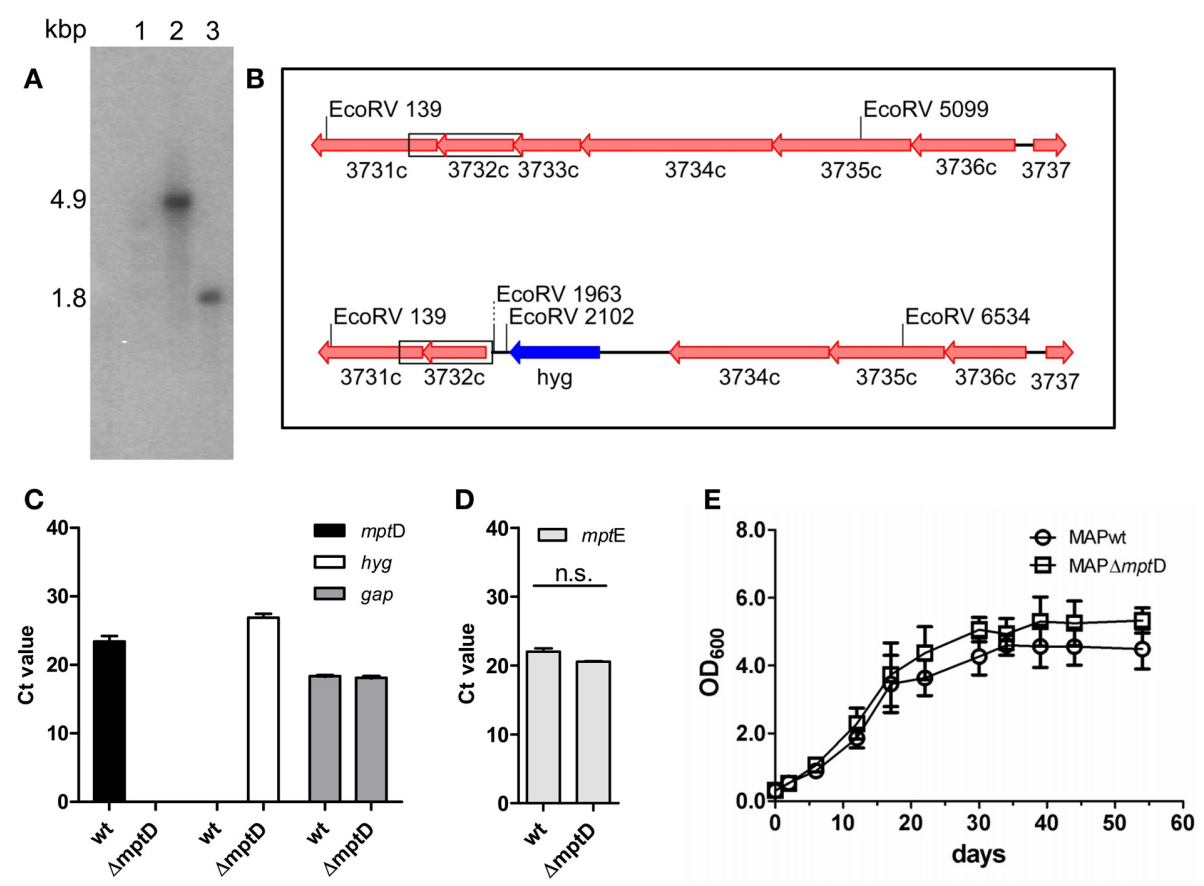

FIGURE 1 | Confirmation and characterization of MAP $\Delta$ mptD mutant by Southern blot analysis (A,B), qRT-PCR (C,D) and growth experiments (E). (A) EcoRV restricted genomic DNA of MAPwt (lane 2) and MAP $\Delta m p t D$ mutant strain (lane 3), Southern blotted and hybridized with a probe against mptE (MAP3732c). In the wild type a $4.9 \mathrm{kbp}$ fragment is labeled, the mutant strain shows a $1.8 \mathrm{kbp}$ fragment. Lane 1 DNA marker. (B) Genomic sketch of the mpt region spanning genes mptF (MAP3731c) to mptA (MAP3736c) in MAPwt (top) and $\triangle m p t D$ mutant strains (bottom). Position of EcoRV restriction sites are indicated, the $\alpha^{32}$-P-dCTP labeled probe fragment is boxed.
(C) Transcription of mptD (black bars) and hygromycin (hyg) (white bars) in MAP wild type (wt) and MAP $\triangle m p t D$ were analyzed by qRT-PCR. As a control, cDNA samples were tested for the housekeeping gene gap (gray bars). (D) Analysis of $m p t$ E (MAP3732c) transcription in MAPwt and MAP $\Delta m p t D$ by qRT-PCR (n.s., no significant difference). (E) Growth of MAPwt and MAP $\triangle m p t D$ in Middlebrook $7 \mathrm{H} 9$ medium. Cultures were inoculated with an initial $\mathrm{OD}_{600}$ of 0.2 and growth was monitored at $\mathrm{OD}_{600}$ (ordinates) at different time points (abscissa) until stationary phase. The results of (C,D) represent the mean \pm standard error (s.e.m.) of three replicates. 
an RNeasyMini kit (Qiagen, Düsseldorf, Germany) with DNase I (50 U) in tube treatment according to the manufacturer's manual. DNAse digested RNA was used for double strand cDNAsynthesis. Briefly, in a total volume of $20 \mu \mathrm{l}, 4 \mu \mathrm{g}$ of RNA were mixed with $0.4 \mu \mathrm{g}$ random primers (Promega, Madison, WI, USA), incubated for $10 \mathrm{~min}$ at $70^{\circ} \mathrm{C}$ in a thermal cycler and subsequently cooled on ice for $5 \mathrm{~min}$. Aliquots $(10 \mu \mathrm{l})$ were mixed with $5 \mu 15 \times$ reaction buffer and $2 \mu l 10 \mathrm{mM}$ dNTP's in a total volume of $25 \mu \mathrm{l}$. Reverse transcription was performed by adding either 200 U MMLV-superscript transcriptase (Promega, Madison, WI, USA) or RNase free water as a negative control. Reactions were incubated for $1 \mathrm{~h}$ at $42^{\circ} \mathrm{C}$, followed by an incubation for $5 \mathrm{~min}$

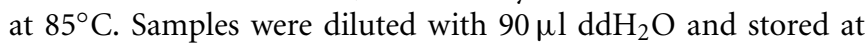
$-20^{\circ} \mathrm{C}$ until further analysis.

For real-time PCR experiments, $2.5 \mu \mathrm{l}$ of cDNA were mixed with $0.4 \mu \mathrm{M}$ primer each and $10 \mu \mathrm{l}$ SYBR-Green Mix (Qiagen, Hilden, Germany) in a total volume of $20 \mu \mathrm{l}$ and subsequently analyzed using a Mx3005P qPCR system (Stratagene, Agilent Technologies, La Jolla, CA, USA) with a thermal cycling profile as follows: segment $1,20 \mathrm{~min}$ at $95^{\circ} \mathrm{C}, 1$ cycle; segment $2,45 \mathrm{~s}$ at $95^{\circ} \mathrm{C}, 1 \mathrm{~min}$ at $58^{\circ} \mathrm{C}, 1 \mathrm{~min}$ at $72^{\circ} \mathrm{C}, 45$ cycles; segment $3,1 \mathrm{~min}$ at $95^{\circ} \mathrm{C}, 30 \mathrm{~s}$ at $55^{\circ} \mathrm{C}, 30 \mathrm{~s}$ at $95^{\circ} \mathrm{C}, 1 \mathrm{cycle}$. Results were normalized to the housekeeping gene gap (MAP1164) and expressed as fold-change to the untreated control.

\section{METABOLOMIC SCREEN}

For metabolomic screening, three independent biological replicates of MAPwt and MAP $\Delta m p t \mathrm{D}$ were grown to mid log phase $\left(\mathrm{OD}_{600}\right.$ of 1.0) in supplemented MB7H9 medium. To stop metabolic activity, $15 \mathrm{ml}$ of each culture were transferred to a quenching solution $\left(60 \%\right.$ methanol kept at $\left.-20^{\circ} \mathrm{C}\right)$ in a dilution of $1: 3$ ( $\mathrm{vol} / \mathrm{vol})$. Bacteria were harvested by centrifugation at $4^{\circ} \mathrm{C}$ at $8000 \times \mathrm{g}$ for $3 \mathrm{~min}$, pellets were washed with $1 \mathrm{ml}$ quenching solution and bacteria were pelleted again. Supernatants were removed and pellets were resuspended in $1 \mathrm{ml} 80 \%$ methanol $\left(-20^{\circ} \mathrm{C}\right)$ for metabolite extraction. Ten microliter of an internal standard $\left(0.2 \mathrm{mg}\right.$ of ${ }^{13} \mathrm{C} 6$ labeled sorbitol in $1 \mathrm{ml}$ methanol) were added to the samples. Samples were transferred to a Fastprep tube and disrupted in a bead beater using four cycles at intensity setting 6.5 for $40 \mathrm{~s}$ with intermediate cooling on ice. Samples were incubated at $70^{\circ} \mathrm{C}$ for $15 \mathrm{~min}$, centrifuged at $4^{\circ} \mathrm{C}$ at $4000 \times \mathrm{g}$ for $15 \mathrm{~min}$, and $10 \mu \mathrm{l}$ were transferred to an appropriate glass tube for freezedrying overnight. Dried samples and $300 \mu \mathrm{l}$ of undried samples were used for gas and liquid chromatography (GC/LC) analyses, respectively. All subsequent steps were carried out at Metabolomic Discoveries GmbH (Potsdam, Germany; www. metabolomicdiscoveries.com). Derivatization and analysis of metabolites in a GC-MS 7890A mass spectrometer (Agilent, Santa Clara, USA) were carried out as described (Lisec et al., 2006). Metabolites were identified in comparison to Metabolomic Discoveries' database entries of authentic standards. The LC separation was performed using hydrophilic interaction chromatography with a ZIC-HILIC $3.5 \mu \mathrm{m}, 200$ A column (Merck Sequant, Umeå, Sweden), operated by an Agilent 1290 UPLC system (Agilent, Santa Clara, CA, USA). The LC mobile phase was a linear gradient from 90 to $70 \%$ acetonitrile over $15 \mathrm{~min}$, followed by a linear gradient from 70 to $10 \%$ acetonitrile over $1 \mathrm{~min}, 3 \mathrm{~min}$ wash with $10 \%$ and $3 \mathrm{~min}$ reequilibration with $90 \%$ acetonitrile. The flow rate was $400 \mu \mathrm{l} / \mathrm{min}$, the injection volume was $1 \mu \mathrm{l}$. The mass spectrometry was performed using a 6540 QTOF/MS Detector (Agilent, Santa Clara, CA, USA). The measured metabolite concentration was normalized to the internal standard. Significant concentration changes of metabolites in different samples were analyzed by normal distribution (Shapiro-Wilk-Test) and variance homogeneity testing (F-Test) using appropriate statistical test procedures (Students test, Welch test, Mann-Whitney test) (see Tables S2A,B). A $p$-value of $p<$ 0.05 was considered as significant.

\section{LIPID PROFILING}

MAPwt and MAP $\Delta m p t \mathrm{D}$ (400 and $600 \mathrm{mg}$ lyophilized cells, respectively) were suspended in $20 \mathrm{ml}$ of a mixture of chloroform/methanol $(2: 1, \mathrm{v} / \mathrm{v})$ and extracted by sonication on ice (Branson sonifier, output 4, duty cycle 40, $2 \times 15 \mathrm{~min}$, pulsed). After centrifugation at $3000 \times g$ for $30 \mathrm{~min}$ at $4^{\circ} \mathrm{C}$, the supernatant was transferred and dried using a rotary evaporator yielding 100 and $170 \mathrm{mg}$ of crude lipids, respectively. The crude lipids were fractionated according to their polarity on $10 \times 1.5 \mathrm{~cm}$ columns filled with Silica gel K60 (0.04-0.063 mm mesh size, Merck, Darmstadt, Germany) sequentially using chloroform, acetone and methanol ( $100 \mathrm{ml}$ each), followed by a final wash with $10 \mathrm{ml}$ of a mix containing equal volumes of chloroform and methanol.

All fractions were evaporated and dry masses determined. The lipid fractions were analyzed on high-performance thinlayer chromatography (HPTLC) plates (Merck, Darmstadt, Germany). Briefly, $10 \mu \mathrm{g}$ of each lipid fraction were applied and resolved either in chloroform/methanol (9:1) or chloroform/methanol/water (65:25:4). Commercial trehalose dimycolate (TDM; Bioclot GmbH, Aidenbach, Germany), and a mixture of phosphoinositol mannosides (PIMs) extracted from M. tuberculosis were included as marker. After evaporation of the solvent, lipid bands were visualized by dipping the plates in a solution of Hanessian's stain [2.5 mM cerium (IV) sulfate, $40 \mathrm{mM}$ ammonium hepta-molybdate in $5.8 \% \mathrm{H}_{2} \mathrm{SO}_{4}$ ] followed by heating to $150^{\circ} \mathrm{C}$ for $5 \mathrm{~min}$.

\section{MACROPHAGE CELL CULTURE AND VIABILITY ASSESSMENT OF INTRACELLULAR MYCOBACTERIA}

The mouse macrophage cell lines J774A.1 (Ralph et al., 1975) and RAW264.7 (Raschke et al., 1978) were maintained in Dulbecco's modified Eagle medium (DMEM) supplemented with 10\% FCS, $1 \%$ glutamine, 100 units $/ \mathrm{ml}$ penicillin, $100 \mu \mathrm{g} / \mathrm{ml}$ streptomycin at $37^{\circ} \mathrm{C}$ and $8 \% \mathrm{CO}_{2}$. For infection experiments, cells were maintained in antibiotic-free DMEM for $48 \mathrm{~h}$. To determine mycobacterial viability during infections, macrophages were infected as described (Kuehnel et al., 2001) with MAPwt and MAP $\Delta m p t D$ in a multiplicity of infection (MOI) of 10:1. After infection at the indicated time points, monolayers were washed twice with PBS and scraped off the plates in $1 \mathrm{ml}$ of $1 \%$ Nonidet P40 in PBS. Cells were disrupted by 10 passages through a 24-gauge needle. A 10 -fold serial dilution of the homogenates was prepared in PBS and $100 \mu$ l of each dilution level were plated on 
supplemented Middlebrook 7H10 agar plates. After incubation for up to 12 weeks at $37^{\circ} \mathrm{C}$, the colony-forming units ( $\mathrm{cfu}$ ) were counted.

\section{BACTERIAL ADHESION ASSAY AND FLOW CYTOMETRY}

Adhesion of mycobacteria was assayed by flow cytometry as described previously (Pott et al., 2009; Basler et al., 2010). Briefly, mycobacteria grown to an $\mathrm{OD}_{600}$ of 1.0 were fluorescently labeled using carboxyfluorescein succinimidyl ester (CFSE, Life Technologies GmbH, Darmstadt, Germany) at $10 \mu \mathrm{M}$ final concentration in $\mathrm{PBS}$ for $20 \mathrm{~min}$ at $37^{\circ} \mathrm{C}$. After two washes in PBS, labeled bacteria were resuspended in DMEM and used for infection of macrophages. To quantify mycobacterial adhesion to J774.A1 macrophages, confluent grown cells were pretreated with latrunculin $(1 \mu \mathrm{g} / \mathrm{ml})$ for $30 \mathrm{~min}$ to inhibit phagocytosis and subsequently incubated for $1 \mathrm{~h}$ with CFSE labeled MAPwt and MAP $\Delta m p t D$ in a MOI of 10:1. Then, bacteria-containing medium was removed, and cells were scraped off in PBS, washed for 5 min with PBS by overhead shaking at $4^{\circ} \mathrm{C}$, and pelleted by centrifugation at $250 \times \mathrm{g}$ for $5 \mathrm{~min}$. Washing was repeated twice. Cells were analyzed with a FACSCalibur (BD biosciences, San Jose, CA, USA). Results were expressed as means \pm standard error of the mean (SEM) fluorescence intensities.

\section{ANIMAL EXPERIMENT}

The mouse infection experiments were approved by the Lower Saxony Federal State Office for Consumer Protection and Food Safety, Germany (reference number 08/1504). Female C57BL/6 mice aged 8 weeks (Charles River, Erkrath, Germany) were used. Mice were infected intraperitonially (i.p.) with an infection dose of $1 \times 10^{8}$ or $2 \times 10^{8}$ pathogens of each strain in $200 \mu \mathrm{l}$ Dulbecco's Phosphate-Buffered Saline (DPBS, Life Technologies $\mathrm{GmbH}$, Darmstadt, Germany; 10 mice per group). Application of PBS was used as negative control. Two days postinfection the body mass monitoring started and was repeated three times per week. After 4 weeks mice were sacrificed, liver, spleen and mesentery tissue were weighted, and MAP (MAPwt and MAP $\Delta m p t \mathrm{D}$ ) were quantified by plating of the homogenized tissue on $\mathrm{MB} 7 \mathrm{H} 10$ agar plates supplemented with 10\% OADC and mycobactin.

Histology was performed in the Mouse Pathology platform at HZI Braunschweig. Briefly, organs were fixed in $10 \%$ formaldehyde (v/v), dehydrated with ethanol, and embedded in paraffin. Paraffin sections $(0.5 \mu \mathrm{m})$ were stained with hematoxylin-eosin (HE) according to standard laboratory procedures. HE stained slices of liver were investigated at $400 \times$ magnification and granuloma counts per area were determined manually using AxioVision Le software (Carl Zeiss AG, Jena, Germany) based on the contrast between granulomas (blue) and other cells of the liver (pink). To minimize false positive results, only granuloma with a size of $>2000 \mu \mathrm{m}^{2}$ were counted and compared to the liver slices of uninfected mice, where no granuloma have been detected.

\section{STATISTICS}

Data are expressed as mean \pm s.e.m. By using GraphPad Prism 4.0 (GraphPad, San Diego, CA, USA) a parametric $t$-test or OneWay ANOVA tests were used for statistical analyses of macrophage and the animal experiment. Differences between treated samples and controls were considered statistically significant at a level of $p<0.05$.

\section{RESULTS CONSTRUCTION OF MAP $\Delta$ mptD}

In order to gain insight into the role of $m p t \mathrm{D}$ in MAP pathogenicity we generated a $\Delta m p t \mathrm{D}$ mutant strain by specialized transduction (Braunstein et al., 2002; Park et al., 2008). For this, the mptD gene (MAP3733c) in MAP strain DSM44135 was replaced by a hygromycin cassette. Hyg-resistant colonies were picked and deletion of $m p t \mathrm{D}$ was confirmed by Southern blot hybridization and qRT-PCR analyses (Figures 1A-C). A positive clone designated MAP $\Delta m p t \mathrm{D}$ was further propagated. To exclude polar effects by the mutation on downstream genes, RNA extracted from $\mathrm{OD}_{600}$ of 1.0 cultures of MAP $\Delta m p t \mathrm{D}$ and MAPwt was analyzed by qRT-PCR. As shown in Figure 1D, the mRNA expression level of the downstream gene mptE (MAP3732c) was not affected in MAP $\Delta m p t \mathrm{D}$, excluding polar effects. On the other hand, this implied that the following genes $m p t \mathrm{E}$ and $m p t \mathrm{~F}$ were not part of the predicted mptABCDEF.

Any illegitimate recombination in MAP $\Delta m p t \mathrm{D}$ could be excluded by PacBio resequencing study applying the RefSeq genome of strain MAP-K10 (NC_002944.1, Li et al., 2005) in the RS_Resequencing.1 protocol of SMRTPortal 2.1.1. Hereby, coverage analysis using samtools mpileup (PMID 19505943) on the resulting BAM-file confirmed no further large-scale deletions in MAP $\Delta m p t$ D. Alignment analyses of PacBio long reads by BLAST confirmed that the hygromycin cassette was inserted nonrecurring and at exactly that position as expected.

Following, we analyzed growth of MAP $\Delta m p t \mathrm{D}$ and MAPwt in supplemented MB7H9 broth (Figure 1E). Both wild type and mutant strains grew with similar kinetics and entered stationary phase after 34 days. This indicated that $m p t \mathrm{D}$ is not necessary for growth of MAP in MB7H9.

\section{REDUCED INTRACELLULAR SURVIVAL OF MAP $\Delta m p t D$ IN MACROPHAGES}

To investigate the potential role of $m p t \mathrm{D}$ in pathogenicity, we performed survival experiments in murine RAW264.7 macrophages and also included J774A.1 macrophages of which we had detailed information of the phagosomal acidification process (Kuehnel et al., 2001). Exponentially grown bacteria of MAP $\Delta m p t \mathrm{D}$ and MAPwt were harvested at an $\mathrm{OD}_{600}$ of 1.0, and single cell suspensions of an $\mathrm{OD}_{600}$ of 0.1 in DMEM were used to infect macrophages as described in Materials and Methods. CFU were counted at $2 \mathrm{~h}, 8$ and 14 days of macrophage infection. Intracellular survival rates were calculated by relating the CFU after 8 and 14 days to those at $2 \mathrm{~h}$. By this, we observed similar intracellular survival rates for MAPwt and MAP $\Delta m p t \mathrm{D}$ representatively shown for RAW264.7 macrophages in Figure 2A. An interesting observation of these experiments was, however, that the number of cultivable MAP $\Delta m p t \mathrm{D}$ after $2 \mathrm{~h}$ of infection was significantly lower as compared to MAPwt (Figure 2B, filled bars). This was true for MAP infection of RAW264.7 and J774A.1 macrophages (Figure 2B). However, incubating MAPwt and MAP $\Delta m p t \mathrm{D}$ in macrophage whole cell lysates for $2 \mathrm{~h}$ led to similar bacterial CFU counts indicating that exponentially 

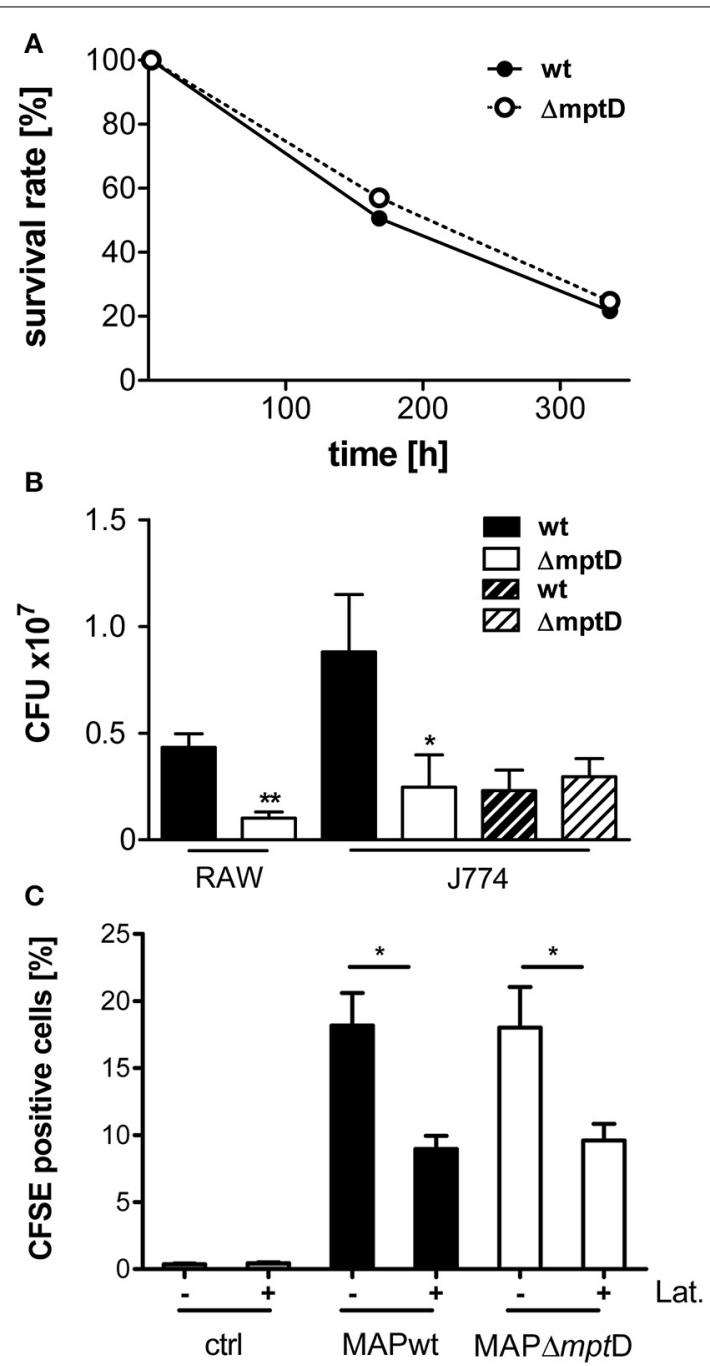

FIGURE 2 | Survival and association of MAPwt and MAP $\Delta m p t D$ strain in mouse macrophages. (A) Survival rates of MAPwt and MAP $\triangle m p t D$ in RAW264.7 macrophages. Exponentially growing bacteria of MAP $\Delta m p t D$ and MAPwt were harvested at $\mathrm{OD}_{600}$ of 1.0, and single cell suspensions of an $\mathrm{OD}_{600}$ of 0.1 in DMEM were used to infect murine RAW264.7

macrophages as described in Materials and Methods. CFU were counted at $2 \mathrm{~h}, 8$ and 14 days of macrophage infection. Intracellular survival rates were calculated by relating the CFU after 8 and 14 days to those of $2 \mathrm{~h}$. (B) CFU numbers of bacteria after infection of mouse macrophages

(RAW264.7/J774.A1) with MAPwt and MAP $\Delta m p t D$ for $2 \mathrm{~h}$ (filled bars) and after incubation of the strains in macrophage cell lysates for $2 \mathrm{~h}$ (dashed bars). The results represent the mean \pm standard error (s.e.m.) of at least three independent replicates for the macrophage infections and two replicates for the incubation in macrophage lysates. (C) Association and invasion of CFSE labeled MAP wild type and MAP $\triangle m p t D$ strains in J774.A1 macrophages after $2 \mathrm{~h}$ incubation with $(+)$ and without $(-)$ latrunculin (Lat.). The statistical analysis was performed using a parametric $t$-test (CFU) or a One-Way ANOVA combined with Dunnett's multiple comparison test (CFSE experiments). A $p$-value $\leq 0.05$ was defined as statistically significant $\left({ }^{* *} p<0.005 ; * p<0.05\right)$.

growing mutant and wild type strain had similar capability to survive in this environment (Figure 2B, dashed bars).

Next we analyzed whether the lower levels of cultivable $\mathrm{MAP} \Delta m p t \mathrm{D}$ after macrophage infection resulted from lower adhesion of MAP $\Delta m p t \mathrm{D}$ to macrophages and/or decreased uptake of MAP $\Delta m p t \mathrm{D}$ by the macrophages. For this, we performed FACS analyses of untreated and latrunculin-treated J774A.1 macrophages incubated with CFSE-labeled MAPwt and MAP $\Delta m p t$ D. Non-infected macrophages were included as negative control. As shown in Figure 2C, no difference between MAPwt and MAP $\Delta m p t$ D bacteria at the level of general association with macrophages (adherent and intracellular mycobacteria) was observed. Also the level of adhesion was similar (Figure 2C, latrunculin treated macrophages). Together these results suggested that the reduced cell number of MAP $\Delta m p t \mathrm{D}$ in macrophage compartments was due to a hampered adaptation of MAP $\Delta m p t \mathrm{D}$ to the early phagosomal environment of macrophages.

\section{MAP $\Delta m p t D$ IS ATTENUATED AFTER PERITONEAL CHALLENGE OF MICE}

The infection experiments of macrophage cultures revealed that MAP $\triangle m p t \mathrm{D}$ is hampered in intracellular survival and indicated that $m p t \mathrm{D}$ might be important for survival in the host. Therefore, to analyze survival of MAP $\Delta m p t \mathrm{D}$ and MAPwt in a more complex system, we infected C57BL/6 mice intraperitoneally with $1 \times 10^{8}$ or $2 \times 10^{8}$ bacteria of exponentially growing cultures of $\mathrm{OD}_{600}$ of 1.0 and animals were sacrified 4 weeks post infection. As shown in Figure 3, compared to the untreated controls, mycobacteria infected mice exhibited increased liver and spleen weight which was more pronounced in the animals infected with the higher infection dose (Figures 3A,D). In lower dose infections, a significant increase in spleen weight was observed in wild type-infected mice but not in mice infected with the mutant (Figure 3D). The CFUs in liver tissue were higher in wild type-infected than in mutant-infected mice (Figure 3B). These differences became significant when the higher infection dose was used. Correspondingly, a higher number of granuloma was counted in HE-stained histological sections (Figure 3C, Suppl. Figure S1), however, no significant difference in granuloma sizes was detected (data not shown). We have recently observed that after i.p. infection of mice, MAP persists in large numbers in mesenteric macrophages (Suwandi et al., in press). Therefore, we also analyzed CFU in the mesentery. As shown in Figure 3E, also in this tissue MAP $\Delta m p t \mathrm{D}$ was isolated in significantly lower numbers than MAPwt. Overall, our animal experiments indicate a significantly lower biological fitness of MAP $\Delta m p t \mathrm{D}$ in the mouse infection model.

\section{MAP $\Delta m p t D$ EXHIBITS AN ALTERED LIPID METABOLISM}

In order to determine the functional cause for the decreased survival of MAP $\Delta m p t \mathrm{D}$ in macrophages and its attenuation in a mouse infection model, comparative metabolomic profiling was performed to detect differences in metabolite concentrations between MAP $\Delta m p t \mathrm{D}$ and its parental strain. The concentrations of 175 metabolites in MAPwt and the MAP $\Delta m p t$ D were compared (Suppl. Table S2). Among the 175 metabolites, the abundances of 32 were significantly different (Figure 4A). Means and standard deviation for the three experiments are shown in Table 1. Different relative abundances for 13 lipids and lipid-intermediates, 5 carbohydrates (mannose, xylose, xylite, tagatose, threitol), 4 amino acids (lysine, arginine, 

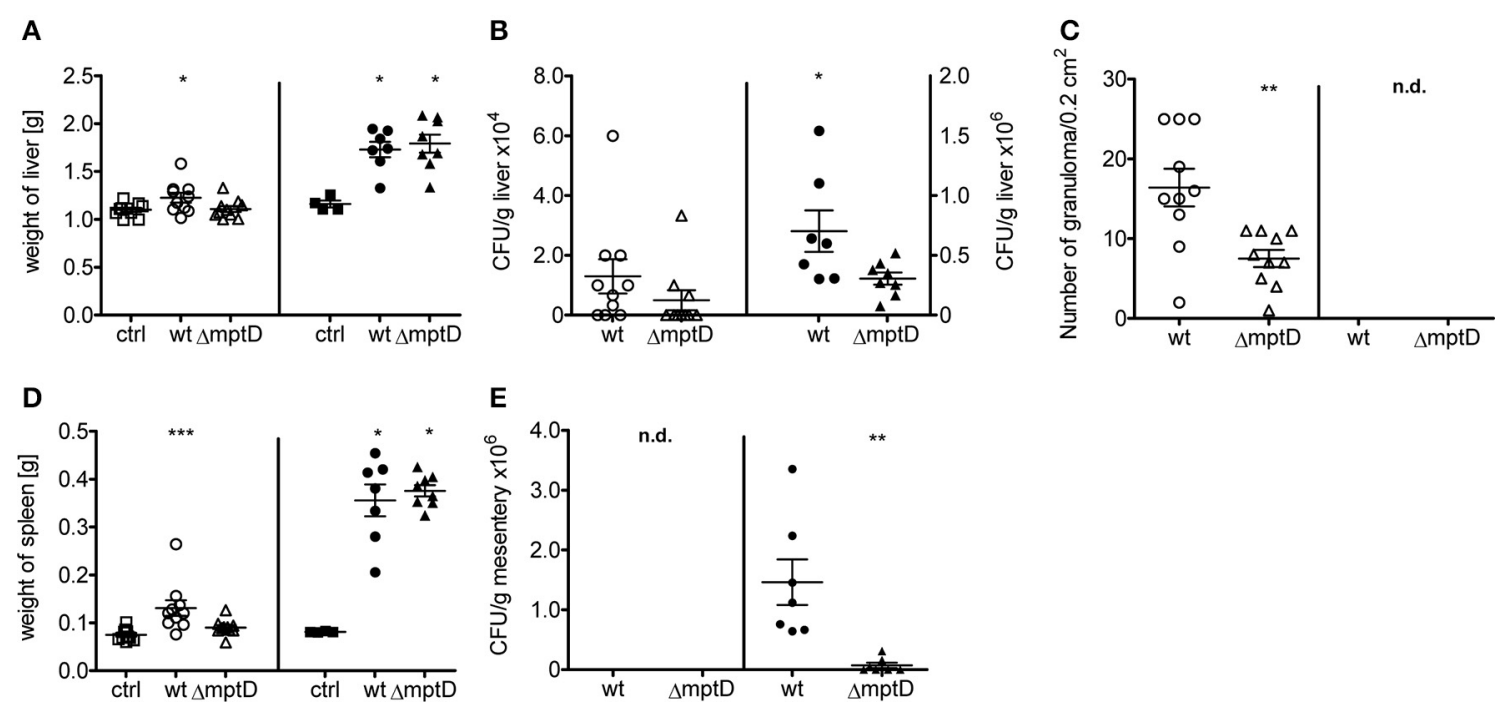

FIGURE 3 | Biological fitness of MAP wild type (MAPwt) and $\Delta m p t$ D mutant strain (MAP $\boldsymbol{\Delta} \boldsymbol{m} \boldsymbol{p} \boldsymbol{t D}$ ) in infected mice. C57BL/6 8 week old female mice were infected with either $1 * 10^{8}$ (open symbols) or $2^{*} 10^{8}$ cells (black symbols) of MAPwt (circle) and MAPAmptD (triangle) for 4 weeks. DPBS buffer was used for the control group (ctrl, squares). The read out parameters for this experiment were the weight of liver $(\mathbf{A})$ and spleen
(D), CFU detection of bacteria from liver (B) and mesentery (E) as well as the amount of granuloma in the liver (C). The results represent the mean \pm standard error (s.e.m.) of animal experiments with 7-10 mice of each group. The statistical analysis was performed using One-Way ANOVA analysis (Kruskal-Wallis test). A $p$-value $\leq 0.05$ was defined as statistically significant $(* * p<0.0005 ; * * p<0.005 ; * p<0.05)$ pyroglutamine, tyrosine), 2 nucleobases (guanine, adenine), 4 nucleotides (adenosine, deoxycytidine, guanosine-5-phosphate, methyladenosine), as well as the abundance of hippurate, citric acid, FAD and the CoA precursor panthetheine were found in MAP $\Delta m p t \mathrm{D}$. Twelve metabolites had a reduced abundance and 20 an increased abundance in MAP $\Delta m p t \mathrm{D}$ (Table 1).

To examine the consequences of the marked differences in lipid metabolites, crude lipids were extracted from MAPwt and MAP $\Delta m p t \mathrm{D}$, fractionated on silica gel columns and analyzed by thin-layer chromatography. In almost all fractions, we found differential band pattern of lipids in MAP $\Delta m p t \mathrm{D}$ compared to its parental strain (Figures $4 \mathrm{~B}, \mathrm{C}$ ). These analyses confirmed the severe changes in lipid metabolism suggested by our metabolic analyses. Overall, these data clearly show the presence of a deregulated lipid metabolism with severe alteration of central metabolic processes in MAP $\Delta m p t \mathrm{D}$.

\section{DISCUSSION}

The pathogenesis of JD is still only partially resolved. In contrast to other pathogenic mycobacteria, MAP is very slow growing and mycobactin-dependent in culture (Merkal and Curran, 1974). Furthermore, unlike the related M. avium ssp. hominissuis, MAP exhibits a strong tissue tropism to the gut which is not seen in other mycobacteria. These phenotypical features might be attributed to MAP-specific genotypical features. Thus, MAP possesses eight common MAP-specific LSPs (Alexander et al., 2009). Thirty-four MAP genes are not present in other mycobacteria species; 13 of these genes are most probably acquired from other Actinomycetales and 21 genes without a homology to other bacteria have been sequenced so far. Although MAP-specific elements are promising candidates for explaining the peculiarities of
MAP, the knowledge concerning their relevance in pathogenicity is poor.

The mptD gene is one of the MAP-specific genes not present in any other yet sequenced mycobacterial species. It is expressed from the $38 \mathrm{~kb}$ pathogenicity island within the LSP14. LSP14 contains mainly genes assigning to metal acquisition (Stratmann et al., 2004; Alexander et al., 2009). This predicted function refers a particular importance to LSP14 as it might contain a putative, alternative iron uptake locus, supplementing for MAP mycobactin deficiency caused by a truncated $m b t$ A gene (Li et al., 2005). In addition to its location on LSP14, the fact that $m p t \mathrm{D}$ was shown to be expressed during infection (Stratmann et al., 2004) suggests a possible role of $m p t \mathrm{D}$ in metabolism in the host environment and in pathogenicity.

Our studies with the $\Delta m p t \mathrm{D}$ mutant strain clearly denote the important standing of $m p t \mathrm{D}$ for MAP metabolism and pathogenicity. We were not able to restore the MAP $\Delta m p t \mathrm{D}$ phenotype by complementation of the MAP $\Delta m p t \mathrm{D}$ with wild-type $m p t \mathrm{D}$ or the complete operon (data not shown), most likely due to the complex organization of the predicted transporter proteins and their yet unknown regulation. Yet we found no evidence for alterations on the genome level except the deletion of the gene itself which might be responsible for the MAP $\Delta m p t \mathrm{D}$ phenotype.

Overall, MAP $\Delta m p t \mathrm{D}$ was considerably hampered with respect to survival in macrophages and in mice. Most probably MAP $\Delta m p t \mathrm{D}$ is not fully able to resist phagosomal factors to which it is exposed during the first $2 \mathrm{~h}$ after infection. This is strongly suggested since the logarithmically grown bacteria showed similar survival after $2 \mathrm{~h}$ of incubation in the macrophage cytosol but the survival of MAP $\Delta m p t \mathrm{D}$ was strongly reduced after 


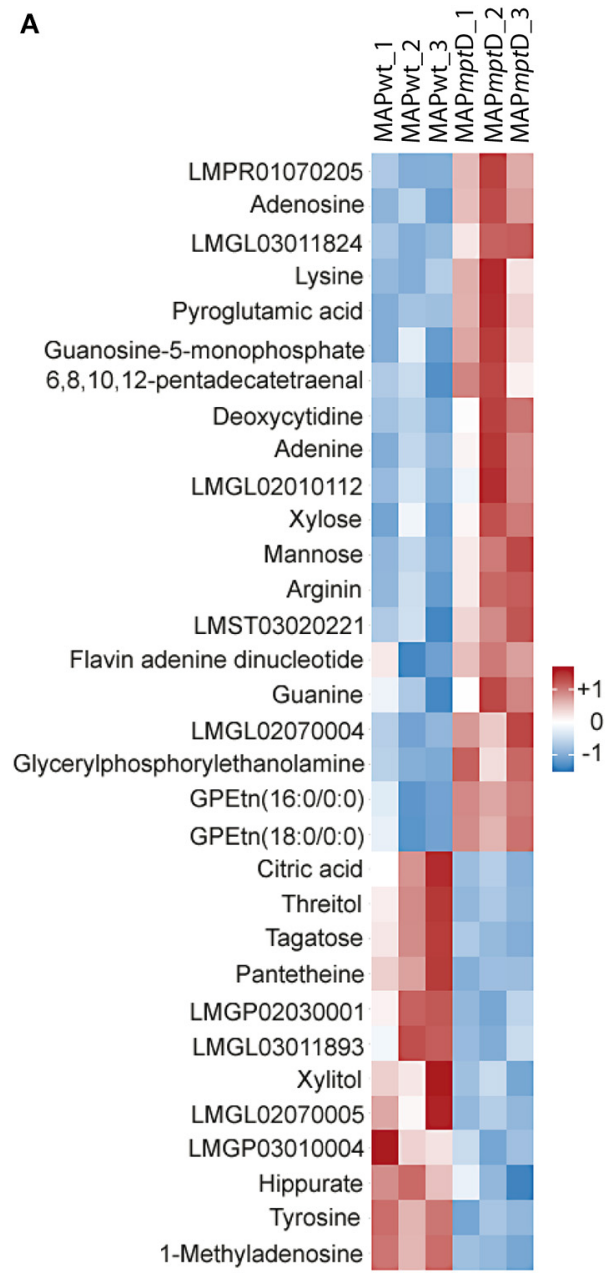

FIGURE 4 | GC/LC-MS analysis of metabolites (A) and HPTLC analysis of lipids (B,C) from MAPwt and MAPAmptD. (A) The heat map illustrates the significant concentration changes (overall results of three biological replicates). The color intensity and tones represent magnitude and direction of metabolic changes, respectively, with the magnitude of change ranging from white (reference) to red (positive deviation to reference) or blue (negative deviation to reference). (B,C) HPTLC analysis of polarity-fractionated lipids. Mobile phase in (B)
B

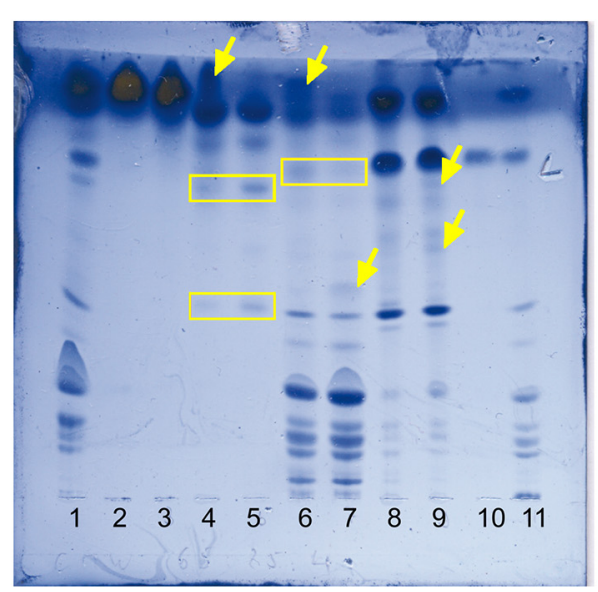

C

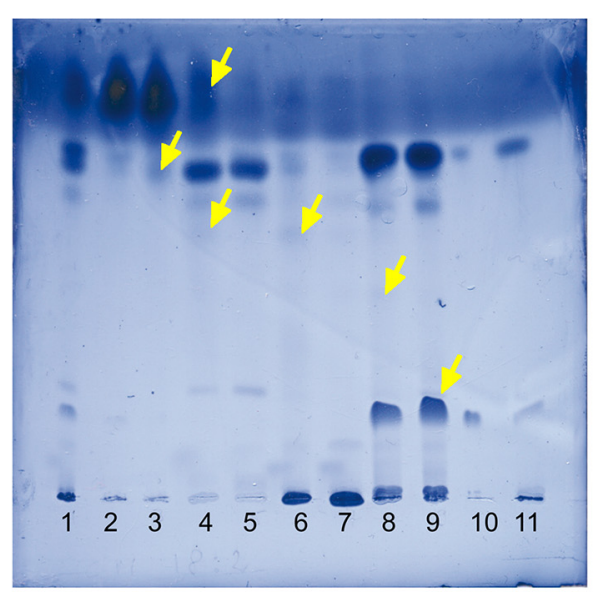

chloroform/methanol 18:2 (v/v); in (C) chloroform/methanol/water 65:25:4 $(v / v / v)$. Lane 1: crude lipids from MAP $\Delta m p t D$; lanes 2, 4, 6 and 8: fractions of MAPwt; lanes 3, 5, 7, and 9: fractions of MAP $\Delta m p t D$; lanes 2 and 3: chloroform fraction; lanes 4 and 5: acetone fraction; lanes 6 and 7: methanol fraction; lanes 8 and 9: chloroform/methanol 1:1 (v/v) column wash; lane 10: TDM standard; Lane 11: PIM standard (see text) yellow arrows = additional bands; yellow boxes $=$ same bands with different intensities.
$2 \mathrm{~h}$ macrophage infection. The observed long-term survival of MAP $\Delta m p t \mathrm{D}$ after infection of macrophages and in mice, however, indicates that the absence of $m p t \mathrm{D}$ does not lead to a general attenuation thereby indicating an important role of $m p t \mathrm{D}$ in early infection immediately after encountering the hostile environment of the early phagocytic vacuole.

Our metabolic analyses clearly show that reduced survival is correlated with an altered metabolism of MAP $\Delta m p t \mathrm{D}$. Metabolic analyses revealed a reduced activity of the TCA cycle in MAP $\Delta m p t \mathrm{D}$ which was indicated by the negative deviation of citric acid. This might be caused by a lower availability of acetylCoA induced by an enhanced acetyl-CoA consuming fatty acid synthesis, which is suggested by the accumulation of nine fatty acid metabolites. In addition, the activity of the TCA cycle appears to be stressed by carbon efflux used for the generation of arginine and lysine. Increased fatty acid synthesis is also reflected by a higher activity of the pentose phosphate pathway which is deducible from the accumulation of nucleosides and FAD. The three fatty acid metabolites with negative deviation and the accumulation of FAD indicate an enhanced $\beta$-oxidation of fatty acids to generate acetyl-CoA in MAP $\Delta m p t \mathrm{D}$ which, however, seems not to satisfy the demand. This metabolic derailment in MAP $\Delta m p t \mathrm{D}$ might be enforced by a diminished CoA availability as indicated by significantly diminished levels of pantetheine, an intermediate for CoA formation. Furthermore differential carbohydrate conversion in MAP $\Delta m p t \mathrm{D}$ is indicated by the accumulation of mannose and xylose, a precursor of arabinose (Wolucka, 2008). Mannose and arabinose are principal 
Table 1 | Relative abundance of significantly differential metabolites (MAP $\Delta$ mptD vs. MAPwt).

\begin{tabular}{|c|c|c|c|}
\hline Metabolite name & Technique & Fold change & Metabolic classification \\
\hline LMGL03011824* & LC & 11.8 & Lipid transport and metabolism \\
\hline Lysine & $\mathrm{GC}$ & 8.0 & Amino acid metabolism \\
\hline LMPR01070205* & LC & 6.5 & Lipid transport and metabolism \\
\hline LMGL02010112* & LC & 5.0 & Lipid transport and metabolism \\
\hline LMFA06000087* & LC & 3.1 & Lipid transport and metabolism \\
\hline Adenosine & LC & 3.0 & Nucleic acid metabolism \\
\hline Arginine & LC & 2.8 & Amino acid metabolism \\
\hline GPEtn(18:0/0:0) & LC & 2.7 & Lipid transport and metabolism \\
\hline Pyroglutamic acid & GC & 2.3 & Amino acid metabolism \\
\hline Guanine & LC & 1.8 & Nucleic acid metabolism \\
\hline Mannose & GC & 1.7 & Carbohydrate metabolism \\
\hline Xylose & $\mathrm{GC}$ & 1.7 & Carbohydrate metabolism \\
\hline Flavin adenine dinucleotide (FAD) & LC & 1.4 & Co-factor metabolism \\
\hline LMGL02070005* & LC & -1.4 & Lipid transport and metabolism \\
\hline Hippuric acid & LC & -1.5 & Amino acid metabolism \\
\hline Xylitol & GC & -1.6 & Carbohydrate metabolism \\
\hline LMGP02030001* & LC & -1.6 & Lipid transport and metabolism \\
\hline Tyrosine & GC & -2.0 & Amino acid metabolism \\
\hline LMGP03010004* & LC & -2.4 & Lipid transport and metabolism \\
\hline
\end{tabular}

* LIPID MAPS ID according to the LIPID MAPS Structure Database (http://www.lipidmaps.org/data/structure/index.htm/).

components of important cell envelope constituents such as lipoamannan (LM), lipoarabinomannan (LAM), and arabinogalactan (Brennan, 2003).

MAP possesses $\sim 300$ genes involved in lipid metabolism and the highest number of redundant genes for this metabolic extent among pathogenic mycobacteria (Li et al., 2005; Marri et al., 2006). The most obvious changes in MAP $\Delta m p t \mathrm{D}$ were seen in the lipid metabolism (Figures $4 \mathrm{~B}, \mathrm{C}$ ). This is in accordance with the reduced survival in macrophages and in mice since fatty acid metabolism in pathogenic mycobacteria has been shown to be essential for the survival of the bacterium in the host (Russell et al., 2010). On the one hand, the solid cell wall with mycolic acids and lipoglycans such as LAM and LM, produced from elongated fatty acids, provides a protective lipid layer (Rowe and Grant, 2006; Hett and Rubin, 2008), on the other hand lipids are implicated as major nutrient sources of pathogenic mycobacteria in the host. Thus, mRNA expression analysis of M. tuberculosis (Mtb) obtained from macrophages in vitro and from the lungs of mice and humans implied that Mtb changes its intermediary metabolism in vivo by using host-derived lipids such as cholesterol during the course of infection rather than using glucose and glycerol, the primary carbon sources metabolized in vitro (Schnappinger et al., 2003; Timm et al., 2003; Talaat et al., 2004). More recently, it was shown that cholesterol degradation appears to be important for feeding Mtb during chronic infection (Miner et al., 2009). Accordingly, we have recently shown that, in the host, MAP increases the activity of the TCA cycle by enhancing $\beta$-oxidation of lipids, most probably cholesterol (Weigoldt et al., 2013).

Our data indicate that a dysfunction of the balanced lipid metabolism necessary for survival of MAP in the host might be responsible for the attenuation of $\mathrm{MAP} \Delta m p t \mathrm{D}$ in macrophages and in mice. The exceptional role of the mycobacterial lipid metabolism for mycobacterial survival has been emphasized in many studies (Russell et al., 2010). Disorders in the lipid homeostasis can dramatically influence mycobacterial viability. For 
example, exhaustive degradation of cholesterol or other lipids may result in the accumulation of stable catabolic intermediates such as propionate which, if not detoxified, may reduce biological fitness (Chang et al., 2009). In addition, within the phagosome, MAP has to resist other microbicidal defense mechanism, e.g., changing levels of bivalent cations such as $\mathrm{Fe}, \mathrm{Cu}, \mathrm{Zn}$ (Soldati and Neyrolles, 2012). The predicted function of $m p t \mathrm{D}$ as part of an $\mathrm{ABC}$ transporter systems and its location on LSP14 suggest $m p t \mathrm{D}$ to be involved in ion homeostasis and imply that bivalent cations may serve as important regulators for balancing lipid metabolism of MAP during adaptation to the intracellular environment. Even though the precise function of $m p t \mathrm{D}$ is not yet known, our study exemplified that MAP-specific elements have a considerable role in MAP metabolism and give novel insights into their importance for metabolic adaptation of MAP to the host environment.

\section{AUTHOR CONTRIBUTIONS}

Ralph Goethe, Gerald-F. Gerlach, and Jochen Meens designed the experiments; Gerald-F. Gerlach and Julia Heinzmann constructed the mutant, Boyke Bunk and Cathrin Spröer performed the mutant sequencing and alignments, Thorsten Meißner and Elke Eckelt characterized the mutant, Thorsten Meißner and Tina Basler performed the macrophage infections, Ralph Goethe and Siegfried Weiss designed the mouse infection experiments, Thorsten Meißner and Abdulhadi Suwandi performed the mouse infections, Sandra Trenkamp performed LC/MS-MS analysis; Walter M. R. Oelemann and Otto Holst performed the lipid profiling, Thorsten Meißner, Elke Eckelt, Jochen Meens, Ralph Goethe analyzed data; and Thorsten Meißner, Elke Eckelt, GeraldF. Gerlach, and Ralph Goethe wrote the paper.

\section{ACKNOWLEDGMENTS}

This work was supported by a grant from the German Research Foundation (DFG, Ge522/6-1). Ralph Goethe and Gerald-F. Gerlach were additionally supported by the German Federal Ministry of Education and Research (BMBF, ZooMAPII: 01KI1003A, 01KI1003B). We thank Regina Engel (RCB) for providing highly purified mycobacterial phosphoinositolmannosides. We are grateful to Sabine Goebel and Kristin Laarmann (TiHo) and Simone Severitt und Nicole Mrotzek (DSMZ) for excellent technical assistance. Walter M. R. Oelemann received a Postdoctoral fellowship of CAPES Foundation, Ministry of Education of Brazil (process no. BEX 1438/11-5).

\section{SUPPLEMENTARY MATERIAL}

The Supplementary Material for this article can be found online at: http://journal.frontiersin.org/journal/10.3389/fcimb. 2014.00110/abstract

\section{REFERENCES}

Alexander, D. C., Turenne, C. Y., and Behr, M. A. (2009). Insertion and deletion events that define the pathogen Mycobacterium avium subsp. paratuberculosis. J. Bacteriol. 191, 1018-1025. doi: 10.1128/JB.01340-08

Atreya, R., Bülte, M., Gerlach, G. F., Goethe, R., Hornef, M., Koehler, H., et al. (2014). Facts, myths and hypotheses on the zoonotic nature of MAP. Int. J. Med. Microbiol. doi: 10.1016/j.ijmm.2014.07.006. (in press).

Bardarov, S., Bardarov, S. Jr., Pavelka, M. S. Jr., Sambandamurthy, V., Larsen, M., Tufariello, J., et al. (2002). Specialized transduction: an efficient method for generating marked and unmarked targeted gene disruptions in Mycobacterium tuberculosis, M. bovis BCG and M. smegmatis. Microbiology 148, 3007-3017.

Bardarov, S., Kriakov, J., Carriere, C., Yu, S., Vaamonde, C., McAdam, R. A., et al. (1997). Conditionally replicating mycobacteriophages: a system for transposon delivery to Mycobacterium tuberculosis. Proc. Natl. Acad. Sci. U.S.A. 94, 10961-10966. doi: 10.1073/pnas.94.20.10961

Basler, T., Brumshagen, C., Beineke, A., Goethe, R., and Baumer, W. (2013). Mycobacterium avium subspecies impair dendritic cell maturation. Innate Immun. 19, 451-461. doi: 10.1177/1753425912470291

Basler, T., Holtmann, H., Abel, J., Eckstein, T., Baumer, W., Valentin-Weigand, P., et al. (2010). Reduced transcript stabilization restricts TNF-alpha expression in RAW264.7 macrophages infected with pathogenic mycobacteria: evidence for an involvement of lipomannan. J. Leukoc. Biol. 87, 173-183. doi: 10.1189/jlb.0309207

Beard, P. M., Daniels, M. J., Henderson, D., Pirie, A., Rudge, K., Buxton, D., et al. (2001). Paratuberculosis infection of nonruminant wildlife in Scotland. J. Clin. Microbiol. 39, 1517-1521. doi: 10.1128/JCM.39.4.1517-1521.2001

Belisle, J. T., and Sonnenberg, M. G. (1998). Isolation of genomic DNA from mycobacteria. Methods Mol. Biol. 101, 31-44.

Braunstein, M., Bardarov, S. S., and Jacobs, W. R. Jr. (2002). Genetic methods for deciphering virulence determinants of Mycobacterium tuberculosis. Methods Enzymol. 358, 67-99. doi: 10.1016/S0076-6879(02)58081-2

Brennan, P. J. (2003). Structure, function, and biogenesis of the cell wall of Mycobacterium tuberculosis. Tuberculosis (Edinb.) 83, 91-97. doi: 10.1016/S1472-9792(02)00089-6

Buergelt, C. D., Hall, C., McEntee, K., and Duncan, J. R. (1978). Pathological evaluation of paratuberculosis in naturally infected cattle. Vet. Pathol. 15, 196-207. doi: 10.1177/030098587801 500206

Burrells, C., Clarke, C. J., Colston, A., Kay, J. M., Porter, J., and Little, D. (1998). A study of immunological responses of sheep clinically-affected with paratuberculosis (Johne's disease). The relationship of blood, mesenteric lymph node and intestinal lymphocyte responses to gross and microscopic pathology. Vet. Immunol. Immunopathol. 66, 343-358. doi: 10.1016/S0165-2427(98) 00201-3

Carriere, C., Riska, P. F., Zimhony, O., Kriakov, J., Bardarov, S., Burns, J., et al. (1997). Conditionally replicating luciferase reporter phages: improved sensitivity for rapid detection and assessment of drug susceptibility of Mycobacterium tuberculosis. J. Clin. Microbiol. 35, 3232-3239.

Carta, T., Alvarez, J., Perez de la Lastra, J. M., and Gortazar, C. (2013). Wildlife and paratuberculosis: a review. Res. Vet. Sci. 94, 191-197. doi: 10.1016/j.rvsc.2012.11.002

Chang, J. C., Miner, M. D., Pandey, A. K., Gill, W. P., Harik, N. S., Sassetti, C. M., et al. (2009). igr Genes and Mycobacterium tuberculosis cholesterol metabolism. J. Bacteriol. 191, 5232-5239. doi: 10.1128/JB.00452-09

Chiodini, R. J., Chamberlin, W. M., Sarosiek, J., and McCallum, R. W. (2012). Crohn's disease and the mycobacterioses: a quarter century later. Causation or simple association?. Crit. Rev. Microbiol. 38, 52-93. doi: 10.3109/1040841X.2011.638273

Clarke, C. J. (1997). The pathology and pathogenesis of paratuberculosis in ruminants and other species. J. Comp. Pathol. 116, 217-261. doi: 10.1016/S00219975(97)80001-1

Cossu, A., Rosu, V., Paccagnini, D., Cossu, D., Pacifico, A., and Sechi, L. A. (2011). MAP3738c and $m p t \mathrm{D}$ are specific tags of Mycobacterium avium subsp. paratuberculosis infection in type I diabetes mellitus. Clin. Immunol. 141, 49-57. doi: 10.1016/j.clim.2011.05.002

Dhama, K., Mahendran, M., Tiwari, R., Dayal, S. S., Kumar, D., Singh, S., et al. (2011). Tuberculosis in birds: insights into the Mycobacterium avium infections. Vet. Med. Int. 2011:712369. doi: 10.4061/2011/ 712369

Dvorska, L., Bull, T. J., Bartos, M., Matlova, L., Svastova, P., Weston, R. T., et al. (2003). A standardised restriction fragment length polymorphism (RFLP) method for typing Mycobacterium avium isolates links IS901 with virulence for birds. J. Microbiol. Methods 55, 11-27. doi: 10.1016/S0167-7012(03) 00092-7

Feller, M., Huwiler, K., Stephan, R., Altpeter, E., Shang, A., Furrer, H., et al. (2007). Mycobacterium avium subspecies paratuberculosis and Crohn's disease: a systematic review and meta-analysis. Lancet Infect. Dis. 7, 607-613. doi: 10.1016/S1473-3099(07)70211-6 
Glanemann, B., Schonenbrucher, H., Bridger, N., Abdulmawjood, A., Neiger, R., and Bulte, M. (2008). Detection of Mycobacterium avium subspecies paratuberculosis-specific DNA by PCR in intestinal biopsies of dogs. J. Vet. Intern. Med. 22, 1090-1094. doi: 10.1111/j.1939-1676.2008. 0147.x

Greenstein, R. J. (2003). Is Crohn's disease caused by a mycobacterium? Comparisons with leprosy, tuberculosis, and Johne's disease. Lancet Infect. Dis. 3, 507-514. doi: 10.1016/S1473-3099(03)00724-2

Greig, A., Stevenson, K., Henderson, D., Perez, V., Hughes, V., Pavlik, I., et al. (1999). Epidemiological study of paratuberculosis in wild rabbits in Scotland. J. Clin. Microbiol. 37, 1746-1751.

Harris, N. B., and Barletta, R. G. (2001). Mycobacterium avium subsp. paratuberculosis in veterinary medicine. Clin. Microbiol. Rev. 14, 489-512. doi: 10.1128/CMR.14.3.489-512.2001

Hett, E. C., and Rubin, E. J. (2008). Bacterial growth and cell division: a mycobacterial perspective. Microbiol. Mol. Biol. Rev. 72, 126-156. doi: 10.1128/MMBR.00028-07

Hostetter, J. M., Steadham, E. M., Haynes, J. S., Bailey, T. B., and Cheville, N. F. (2002). Cytokine effects on maturation of the phagosomes containing Mycobacteria avium subspecies paratuberculosis in J774 cells. FEMS Immunol. Med. Microbiol. 34, 127-134. doi: 10.1111/j.1574-695X.2002.tb00613.x

Ignatov, D., Kondratieva, E., Azhikina, T., and Apt, A. (2012). Mycobacterium avium-triggered diseases: pathogenomics. Cell. Microbiol. 14, 808-818. doi: 10.1111/j.1462-5822.2012.01776.x

Kreeger, J. M. (1991). Ruminant paratuberculosis-a century of progress and frustration. J. Vet. Diagn. Invest. 3, 373-382. doi: 10.1177/104063879100 300425

Kuehnel, M. P., Goethe, R., Habermann, A., Mueller, E., Rohde, M., Griffiths, G., et al. (2001). Characterization of the intracellular survival of Mycobacterium avium ssp. paratuberculosis: phagosomal $\mathrm{pH}$ and fusogenicity in $\mathrm{J774}$ macrophages compared with other mycobacteria. Cell. Microbiol. 3, 551-566. doi: 10.1046/j.1462-5822.2001.00139.x

Li, L., Bannantine, J. P., Zhang, Q., Amonsin, A., May, B. J., Alt, D., et al. (2005). The complete genome sequence of Mycobacterium avium subspecies paratuberculosis. Proc. Natl. Acad. Sci. U.S.A. 102, 12344-12349. doi: 10.1073/pnas.0505662102

Lisec, J., Schauer, N., Kopka, J., Willmitzer, L., and Fernie, A. R. (2006). Gas chromatography mass spectrometry-based metabolite profiling in plants. Nat. Protoc. 1, 387-396. doi: 10.1038/nprot.2006.59

Marri, P. R., Bannantine, J. P., and Golding, G. B. (2006). Comparative genomics of metabolic pathways in Mycobacterium species: gene duplication, gene decay and lateral gene transfer. FEMS Microbiol. Rev. 30, 906-925. doi: 10.1111/j.15746976.2006.00041.x

Mendoza, J. L., Lana, R., and Diaz-Rubio, M. (2009). Mycobacterium avium subspecies paratuberculosis and its relationship with Crohn's disease. World J. Gastroenterol. 15, 417-422. doi: 10.3748/wjg.15.417

Merkal, R. S., and Curran, B. J. (1974). Growth and metabolic characteristics of Mycobacterium paratuberculosis. Appl. Microbiol. 28, 276-279.

Mijs, W., de Haas, P., Rossau, R., van der, L. T., Rigouts, L., Portaels, F., et al. (2002). Molecular evidence to support a proposal to reserve the designation Mycobacterium avium subsp. avium for bird-type isolates and 'M. avium subsp. hominissuis' for the human/porcine type of M. avium. Int. J. Syst. Evol. Microbiol. 52, 1505-1518. doi: 10.1099/ijs.0.02037-0

Miner, M. D., Chang, J. C., Pandey, A. K., Sassetti, C. M., and Sherman, D. R. (2009). Role of cholesterol in Mycobacterium tuberculosis infection. Indian J. Exp. Biol. 47, 407-411.

Naser, S. A., Sagramsingh, S. R., Naser, A. S., and Thanigachalam, S. (2014). Mycobacterium avium subspecies paratuberculosis causes Crohn's disease in some inflammatory bowel disease patients. World J. Gastroenterol. 20, 7403-7415. doi: 10.3748/wjg.v20.i23.7403

Park, K. T., Dahl, J. L., Bannantine, J. P., Barletta, R. G., Ahn, J., Allen, A. J., et al. (2008). Demonstration of allelic exchange in the slow-growing bacterium Mycobacterium avium subsp. paratuberculosis, and generation of mutants with deletions at the pknG, relA, and lsr2 loci. Appl. Environ. Microbiol. 74, 1687-1695. doi: 10.1128/AEM.01208-07

Pott, J., Basler, T., Duerr, C. U., Rohde, M., Goethe, R., and Hornef, M. W. (2009). Internalization-dependent recognition of Mycobacterium avium ssp. paratuberculosis by intestinal epithelial cells. Cell. Microbiol. 11, 1802-1815. doi: 10.1111/j.1462-5822.2009.01372.x
Ralph, P., Prichard, J., and Cohn, M. (1975). Reticulum cell sarcoma: an effector cell in antibody-dependent cell-mediated immunity. J. Immunol. 114, 898-905.

Rani, P. S., Sechi, L. A., and Ahmed, N. (2010). Mycobacterium avium subsp. paratuberculosis as a trigger of type-1 diabetes: destination Sardinia, or beyond? Gut Pathog. 2, 1. doi: 10.1186/1757-4749-2-1

Raschke, W. C., Baird, S., Ralph, P., and Nakoinz, I. (1978). Functional macrophage cell lines transformed by Abelson leukemia virus. Cell 15, 261-267. doi: 10.1016/0092-8674(78)90101-0

Rosenfeld, G., and Bressler, B. (2010). Mycobacterium avium paratuberculosis and the etiology of Crohn's disease: a review of the controversy from the clinician's perspective. Can. J. Gastroenterol. 24, 619-624.

Rowe, M. T., and Grant, I. R. (2006). Mycobacterium avium ssp. paratuberculosis and its potential survival tactics. Lett. Appl. Microbiol. 42, 305-311. doi: 10.1111/j.1472-765X.2006.01873.x

Russell, D. G., VanderVen, B. C., Lee, W., Abramovitch, R. B., Kim, M. J., Homolka, S., et al. (2010). Mycobacterium tuberculosis wears what it eats. Cell Host Microbe 8, 68-76. doi: 10.1016/j.chom.2010.06.002

Rustad, T. R., Roberts, D. M., Liao, R. P., and Sherman, D. R. (2009). Isolation of mycobacterial RNA. Methods Mol. Biol. 465, 13-21. doi: 10.1007/978-1-59745207-6_2

Ryan, A., Keany, S., Eleftheriadou, O., Ballet, R., Cheng, H. Y., and Sim, E. (2014). Mechanism-based inhibition of HsaD: a C-C bond hydrolase essential for survival of Mycobacterium tuberculosis in macrophage. FEMS Microbiol. Lett. 350, 42-47. doi: 10.1111/1574-6968.12302

Sambrook, J., and Russell, D. W. (2001). Molecular Cloning: A Laboratory Manual, $3 r d$ Edn. Cold Sping Harbor, NY: Cold Spring Harbor Laboratory.

Schnappinger, D., Ehrt, S., Voskuil, M. I., Liu, Y., Mangan, J. A., Monahan, I. M., et al. (2003). Transcriptional adaptation of Mycobacterium tuberculosis within Macrophages: insights into the Phagosomal environment. J. Exp. Med. 198, 693-704. doi: 10.1084/jem.20030846

Shin, S. J., Wu, C. W., Steinberg, H., and Talaat, A. M. (2006). Identification of novel virulence determinants in Mycobacterium paratuberculosis by screening a library of insertional mutants. Infect. Immun. 74, 3825-3833. doi: 10.1128/IAI.0174205

Soldati, T., and Neyrolles, O. (2012). Mycobacteria and the intraphagosomal environment: take it with a pinch of salt(s)! Traffic 13, 1042-1052. doi: 10.1111/j.1600-0854.2012.01358.x

Stief, B., Mobius, P., Turk, H., Horugel, U., Arnold, C., and Pohle, D. (2012). Paratuberculosis in a miniature donkey (Equus asinus f. asinus). Berl. Munch. Tierarztl. Wochenschr. 125, 38-44.

Stratmann, J., Strommenger, B., Goethe, R., Dohmann, K., Gerlach, G. F., Stevenson, K., et al. (2004). A 38-kilobase pathogenicity island specific for Mycobacterium avium subsp. paratuberculosis encodes cell surface proteins expressed in the host. Infect. Immun. 72, 1265-1274. doi: 10.1128/IAI.72.3.12651274.2004

Suwandi, A., Bargen, I., Roy, B., Pils, M. C., Krey, M., zur Lage, S., et al. (in press). Experimental colitis is exacerbated by concomitant infection with Mycobacterium avium ssp. paratuberculosis. Inflamm. Bowel Dis.

Talaat, A. M., Lyons, R., Howard, S. T., and Johnston, S. A. (2004). The temporal expression profile of Mycobacterium tuberculosis infection in mice. Proc. Natl. Acad. Sci. U.S.A. 101, 4602-4607. doi: 10.1073/pnas.03060 23101

Thorel, M. F., Krichevsky, M., and Levy-Frebault, V. V. (1990). Numerical taxonomy of mycobactin-dependent mycobacteria, emended description of Mycobacterium avium, and description of Mycobacterium avium subsp. avium subsp. nov., Mycobacterium avium subsp. paratuberculosis subsp. nov., and Mycobacterium avium subsp. silvaticum subsp. nov. Int. J. Syst. Bacteriol. 40, 254-260. doi: 10.1099/00207713-40-3-254

Timm, J., Post, F. A., Bekker, L. G., Walther, G. B., Wainwright, H. C., Manganelli, R., et al. (2003). Differential expression of iron-, carbon-, and oxygenresponsive mycobacterial genes in the lungs of chronically infected mice and tuberculosis patients. Proc. Natl. Acad. Sci. U.S.A. 100, 14321-14326. doi: $10.1073 /$ pnas. 2436197100

Vergne, I., Chua, J., Singh, S. B., and Deretic, V. (2004). Cell biology of Mycobacterium tuberculosis phagosome. Annu. Rev. Cell Dev. Biol. 20, 367-394. doi: 10.1146/annurev.cellbio.20.010403.114015

Weigoldt, M., Meens, J., Bange, F. C., Pich, A., Gerlach, G. F., and Goethe, R. (2013). Metabolic adaptation of Mycobacterium avium subsp. paratuberculosis to the gut environment. Microbiology 159, 380-391. doi: 10.1099/mic.0.062737-0 
Weigoldt, M., Meens, J., Doll, K., Fritsch, I., Mobius, P., Goethe, R., et al. (2011). Differential proteome analysis of Mycobacterium avium subsp. paratuberculosis grown in vitro and isolated from cases of clinical Johne's disease. Microbiology 157, 557-565. doi: 10.1099/mic.0.044859-0

Wolucka, B. A. (2008). Biosynthesis of D-arabinose in mycobacteria-a novel bacterial pathway with implications for antimycobacterial therapy. FEBS J. 275, 2691-2711. doi: 10.1111/j.1742-4658.2008.06395.x

zur Lage, S., Goethe, R., Darji, A., Valentin-Weigand, P., and Weiss, S. (2003). Activation of macrophages and interference with CD4+ T-cell stimulation by Mycobacterium avium subspecies paratuberculosis and Mycobacterium avium subspecies avium. Immunology 108, 62-69. doi: 10.1046/j.13652567.2003.01564.x

Conflict of Interest Statement: The authors declare that the research was conducted in the absence of any commercial or financial relationships that could be construed as a potential conflict of interest.
Received: 28 May 2014; accepted: 25 July 2014; published online: 14 August 2014. Citation: Meißner T, Eckelt E, Basler T, Meens J, Heinzmann J, Suwandi A, Oelemann WMR, Trenkamp S, Holst O, Weiss S, Bunk B, Spröer C, Gerlach G-F and Goethe R (2014) The Mycobacterium avium ssp. paratuberculosis specific mptD gene is required for maintenance of the metabolic homeostasis necessary for full virulence in mouse infections. Front. Cell. Infect. Microbiol. 4:110. doi: 10.3389/fcimb.2014.00110

This article was submitted to the journal Frontiers in Cellular and Infection Microbiology.

Copyright (C) 2014 Meißner, Eckelt, Basler, Meens, Heinzmann, Suwandi, Oelemann, Trenkamp, Holst, Weiss, Bunk, Spröer, Gerlach and Goethe. This is an open-access article distributed under the terms of the Creative Commons Attribution License (CC BY). The use, distribution or reproduction in other forums is permitted, provided the original author(s) or licensor are credited and that the original publication in this journal is cited, in accordance with accepted academic practice. No use, distribution or reproduction is permitted which does not comply with these terms. 